\title{
Multicenter European Prevalence Study of Neurocognitive Impairment and Associated Factors in HIV Positive Patients
}

\author{
Lewis J. Haddow ${ }^{1}$ Rosanna Laverick ${ }^{1} \cdot$ Marina Daskalopoulou $^{1} \cdot$ \\ Jeffrey McDonnell ${ }^{2}$ - Fiona C. Lampe ${ }^{1} \cdot$ Richard Gilson $^{1} \cdot$ Andrew Speakman $^{1}$. \\ Andrea Antinori ${ }^{3}$ - Pietro Balestra ${ }^{3}$. Tina Bruun ${ }^{4} \cdot$ Jan Gerstoft $^{4}$. \\ Lars Nielsen $^{5} \cdot$ Anna Vassilenko $^{6} \cdot$ Simon Collins $^{7} \cdot$ Alison J. Rodger $^{1} \cdot$ \\ For the Cognitive Impairment in People with HIV in the European Region (CIPHER) \\ Study Group
}

Published online: 31 January 2017

(c) The Author(s) 2017. This article is published with open access at Springerlink.com

\begin{abstract}
We conducted a cross-sectional study in 448 HIV positive patients attending five European outpatient clinics to determine prevalence of and factors associated with neurocognitive impairment (NCI) using computerized and penand-paper neuropsychological tests. NCI was defined as a normalized $Z$ score $\leq-1$ in at least 2 out of 5 cognitive domains. Participants' mean age was 45.8 years; $84 \%$ male; $87 \%$ white; $56 \%$ university educated; median CD4 count 550 cells $/ \mathrm{mm}^{3} ; 89 \%$ on antiretroviral therapy. $156(35 \%)$ participants had NCI, among whom $26(17 \% ; 5.8 \%$ overall $)$ reported a decline in activities of daily living. Prevalence of NCI was lower in those always able to afford basic needs (adjusted prevalence ratio $[\mathrm{aPR}] 0.71,95 \%$ confidence interval [CI] $0.54-0.94)$ or with a university education (aPR $0.72,95 \%$ CI $0.54-0.97)$ and higher in those with severe depressive symptoms (aPR 1.53, 95\% CI 1.09-2.14) or a significant comorbid condition (aPR 1.40, 95\% CI 1.03-1.90).
\end{abstract}

Lewis J. Haddow

lewis.haddow@ucl.ac.uk

1 Research Department of Infection and Population Health, Mortimer Market Centre, University College London, Capper Street, London WC1E 6JB, UK

2 Department of Psychology, King's College London, London, UK

3 National Institute for Infectious Diseases, Lazzaro Spallanzani, Rome, Italy

4 Department of Infectious Diseases, Rigshospitalet, Centre for Health \& Infectious Disease Research (CHIP), University of Copenhagen, Copenhagen, Denmark

5 Infektionsmedicinsk Afdeling, Nordsjællands Hospital, Hillerød, Denmark

6 Belarusian State Medical University, Minsk, Belarus

7 HIV i-Base, London, UK
Resumen Reportamos un estudio de tipo corte transversal que incluye 448 pacientes VIH seropositivos vistos en cinco clínicas especializadas en Europa con el objetivo de medir la prevalencia del trastorno neurocognitivo asociado al VIH (NCI por sus siglas en inglés) y los factores de riesgo asociados a éste. Se usaron pruebas neuropsicológicas computarizadas y en papel para determinar la presencia de NCI, definido como puntuación $\mathrm{Z} \leq 1$ en al menos 2 de los 5 dominios cognitivos evaluados. La media de edad de los pacientes fue 45,8 años, $84 \%$ eran hombres, $87 \%$ blancos y $56 \%$ tenían educación universitaria. La media de CD4 fue de $550 \mathrm{cel} / \mathrm{mm}^{3}$ y $89 \%$ de los pacientes recibían terapia antiretroviral. Un total de $156(35 \%)$ participantes tenían NCI, de los cuales 26 (17\%, 5,8\% de la población de estudio) reportaron deterioro en actividades de la vida diaria. La prevalencia de NCI fue menor en participantes capaces de cubrir sus necesidades básicas (Razón de prevalencia ajustada [aPR] 0,71; Intervalo de confianza del $95 \%$ [95\% CI] 0,54-0,94) o con educación universitaria (aPR 0,72 ; 95\% CI 0,54-0,97) pero fue mayor en aquellos con síntomas de depresión severa (aPR 1,53; 95\% CI 1,09-2,14) o alguna comorbilidad importante (aPR 1,40 ; 95\% CI 1,03-1,90).

Keywords HIV · Prevalence · HIV dementia · Neuropsychological assessment $\cdot$ MCI (mild cognitive impairment) $\cdot$ Activities of daily living

\section{Introduction}

HIV-1 can cause neurological disease, but severe impairment is rare in HIV positive (HIV+) patients with access to antiretroviral therapy (ART) [1]. A variety of estimates of prevalence of milder neurocognitive impairment (NCI) 
have been reported in HIV+ patients, exceeding $50 \%$ in studies from Western Europe and North America [2-4], but as low as $19 \%$ in other studies using broadly similar neuropsychological (NP) definitions $[5,6]$. Estimates may vary because of differences in the characteristics of study populations. Most studies have focused on a particular setting (such as clinical trial participants $[5,7,8]$, a single country $[2-7,9]$, or a specific patient group $[6,10])$, and many studies have specifically excluded participants with potentially confounding conditions, detectable viral load or low CD4 count $[2,5,7,9,11]$. There is a need to study more diverse HIV + populations inclusive of those with typical comorbid conditions to clarify the effects of clinical, psychological and social variables as risk factors. As well as differences between study populations, differences in assessment method may lead to variations in results. Despite efforts to standardize definitions of HIV-associated NCI, for example with the "Frascati criteria" [12] or with a threshold in global deficit score (GDS) [13], there may be important differences between measuring instruments. The use of computerized neuropsychological testing batteries is one method that may provide stable and cross-cultural measures of cognitive function [14-17].

Our primary aim was to estimate prevalence of NCI, using mainly computerized assessment, in HIV+ outpatient samples in four European countries (UK, Italy, Denmark and Belarus). Our secondary aim was to assess associations of clinical and social variables with NCI, in order to identify potentially modifiable risk factors for NCI in HIV+ patients.

\section{Methods}

\section{Participants}

CIPHER is a five-center European study of HIV+ outpatients (two clinics in London, UK, and one clinic in each of: Copenhagen, Denmark; Minsk, Belarus; Rome, Italy). Participants were sampled opportunistically at the time of routine outpatient attendance from May 2011 to January 2013. Participants had to be at least 18 years of age and able to give consent and complete study procedures. They were recruited regardless of symptoms, treatment and comorbidities.

\section{Neurocognitive and Functional Status Assessments}

The study used Cogstate, software adapted from standard NP tasks for assessment of multiple cognitive domains (http://cogstate.com/academic-2/measurement-of-cognition) [18-20], and two pen-and-paper NP tests. The self-completed tests are mainly non-language-based and the stimuli vary randomly between assessments, reducing the influence of cultural, educational, and practice effects. Computerized NP testing is widespread in research and clinical practice, and several studies have used Cogstate in HIV+ patients in Anglophone countries [5, 14, 15, 21-24], with some work demonstrating good construct validity and correlation with traditional pen-and-paper NP batteries $[14,15,21]$. Ten tests were conducted; these were organized into five domains: psychomotor speed (detection and identification tests); verbal memory (Shopping List learning and recall tests); executive function (Groton Maze learning and recall tests; these tests also assess visuospatial learning and memory); working memory (One-Back speed and accuracy tests); verbal fluency (two pen-and-paper tests: controlled oral word association test [COWAT] and category fluency test [CFT]). The battery was designed to be reliable and standardized across sites, and a single researcher conducted the same training for assessors at all sites. Testing included a full practice run, which was not scored, on the same day as the main assessment. The practice and main assessment took around $90 \mathrm{~min}$ in total, not including rest breaks. Analysis of serial testing with Cogstate suggests an early practice effect between the first and second runs, and subsequent stabilization even with short time intervals [25]. The use of a practice run prior to the main assessment optimizes performance while minimizing practice effects and is recommended by the manufacturer's Research Manual.

Functional status was measured using a self-completed questionnaire, the Modified Lawton \& Brody Instrumental Activities of Daily Living Scale, which required participants to indicate their current and best ever level of function on 16 activities of daily living (ADL) such as cooking, shopping, managing finances and taking medication. Where decline had occurred, participants were asked to record the perceived cause as physical, cognitive, or both. The questionnaire has been used in large published studies of HAND [3] and shows good correlation with the Karnofsky score and performance-based measures of function [26].

\section{Other Data Collection}

All participants were attending clinic regularly for HIV care. They completed a questionnaire including demographic, socio-economic and HIV-related factors, depression and anxiety symptom scales (PHQ-9 and GAD-7), medical history, and recreational drug and alcohol use. PHQ-9 scores were graded as: 0-4, none/minimal depression; 5-9, mild; 10-14, moderate; 15-19, moderate-severe; 20-27, severe. GAD-7 scores were graded as: $0-4$, none/ minimal anxiety; 5-9, mild; 10-14, moderate; 15-21, severe. Problem drinking was defined by the modified 
(two-question) AUDIT-C questionnaire: a positive score was $\geq 5$ points for men or $\geq 4$ points for women. Financial hardship was assessed by the question "Do you have enough money to cover your basic needs?" Respondents could answer always, most of the time, some of the time, or no, and any answer other than "always" was considered to be positive for this analysis. Additional information collected from clinical and laboratory records at the time of assessment included HIV viral load (VL), CD4 count, ART use, AIDS-defining illnesses, lipids, glucose, liver function tests, and details of neurological, cardiovascular and psychiatric comorbidities. Hepatitis $\mathrm{C}$ virus (HCV) status was defined by the most recent HCV RNA assay, or the most recent antibody result in the absence an RNA result.

\section{Measures and Definitions}

Each cognitive test score was converted to an age-, sex-, and education-standardized $Z$-score using normative means and SD. Normative general population data for the computerized tests were provided by Cogstate from Europe, United States of America, South East Asia, Australia and New Zealand, stratified by age group (18-34, 35-50, and $51+$ years; minimum cell size $\mathrm{n}=145$ ), sex (157 female, 377 male), and education (university/further education, $\mathrm{n}=243$, or secondary school, $\mathrm{n}=291$ ). Exclusion criteria for the normative data included any clinically significant neurological, psychiatric or other disease, impaired visual or auditory acuity, and routine use of neurologically active medications, and assessments had been conducted in the individual's first language. All or subsets of this normative data had been used previously to classify cognitive function in HIV+ adults [5, 15, 21, 22, 24]. Published age-, sex- and education-stratified norms were used for the COWAT and CFT [27, 28].

Scores for each of the five domains were categorized as severely impaired $(Z \leq-2)$, mildly impaired $(-2<Z \leq$ $-1)$, or normal $(Z>-1)$. NCI was defined as at least mild impairment in at least 2 out of 5 cognitive domains. We excluded participants with fewer than 5 gradable domains. In addition, we defined grades of impairment, based on Frascati criteria: HIV-Associated Dementia (HAD), severely impaired in at least 2 cognitive domains with significant functional decline (decline in $\geq 4 \mathrm{ADL}$, reported by the patient to result from cognitive difficulties); Mild Neurocognitive Disorder (MND), NCI with at least mild functional decline (defined as decline in 2-3 ADL) but not meeting criteria for HAD; Asymptomatic Neurocognitive Impairment (ANI), NCI with no functional decline (maximum of one ADL affected). Strict application of the Frascati criteria demands that there is no evidence of a pre-existing cause for the impairment and suggests that assessment be revisited when the comorbid condition has resolved.
Therefore, participants with any of a pre-specified list of conditions were noted but not excluded from analysis. The full list of conditions was published as an appendix to the original criteria [12] and includes depressive disorders, historical traumatic brain injury, developmental disabilities, alcohol and substance use disorders, certain HIV-related and non-HIV-related neurologic conditions, and systemic disease likely to affect cognition (including HCV infection). We adopted the nomenclature used by the CHARTER group, where contributing conditions were those deemed to have potential for mild cognitive impairment, while confounding conditions were those likely to have a substantial effect on cognitive function [3].

\section{Statistical Analyses}

Participant characteristics were compared between countries using the exact test for categorical variables, ANOVA for normally-distributed continuous variables, and the KruskalWallis test for non-normally-distributed continuous variables and ordinal scales. Prevalence of NCI with $95 \%$ confidence intervals (CI) was calculated. Modified Poisson regression analyses were used to assess unadjusted and adjusted prevalence ratios for factors associated with NCI, with CIs calculated from robust standard errors [29]. We did not use the Frascati criteria for these analyses because we wished to estimate the associations with factors that would affect the outcome measure (such as depression and confounding conditions). The associations of five variables with NCI were estimated (age, sex, education, and presence of confounding and contributing conditions). Then individual analyses of other clinical and psychosocial variables were performed, with adjustment for age, sex, education and confounding conditions. Finally, all variables found to be associated with NCI $(\mathrm{P} \leq 0.1)$ in either of the earlier models were incorporated into a multivariable analysis. Because depression and anxiety symptom scores were highly collinear, only the stronger of these two variables was included in the final model.

To explore which cognitive domains were driving associations between risk factors and the global measure of NCI, factors associated with the raw scores on each neurocognitive test were assessed in separate models. In these models, the main variables of age, sex, education and confounding conditions and all variables noted to be related to global NCI in subsequent analyses were included in a multivariable model.

\section{Results}

\section{Study Population}

Of 486 patients recruited, 448 (92\%) completed both practice and baseline assessments (London, 292 [65\%]; 
Rome 90 [20\%]; Copenhagen 42 [9.4\%]; Minsk 24 [5.4\%]). The remainder were excluded from further analysis: 15 participants who only completed the practice assessment and 23 who did not complete all five cognitive domains. The sample was $87 \%$ white, $84 \%$ male, and mean 45.8 years of age (SD 9.6). $89 \%$ were on ART, of whom $91 \%$ had $\mathrm{VL}<50$ copies $/ \mathrm{mL}$ ( $81 \%$ overall). The sites differed significantly on many characteristics (Table 1): participants in Minsk had the youngest age, lowest CD4 count, lowest proportion undetectable on ART and shortest time since HIV diagnosis, while Rome had the lowest proportion of university-educated participants, and London had the highest proportion of non-white participants and migrants. Rome and Minsk had a higher proportion of injection drug users, while problem drinking and recent recreational non-injection drug use were particularly prevalent in London. Moderate to severe depressive symptoms were present in a quarter of patients, and anxiety symptoms of similar severity in a fifth. Antidepressants or psychotherapy were being prescribed to $37 \%$ of those with moderate/severe symptoms and $10 \%$ of those with no or mild symptoms ( $16 \%$ overall).

\section{Prevalence of NCI and Functional Impairment}

Of 448 participants, $156(35 \%)$ met the definition of NCI (at least mild impairment in at least 2 out of 5 cognitive domains). Of those with NCI, 39 (25\%) had confounding conditions, the most common being major substance use disorders $(n=22)$, AIDS-defining conditions of the CNS $(\mathrm{n}=8)$, and severe ongoing depression $(\mathrm{n}=12)$. Of 292 patients not meeting the definition of NCI, 42 (14\%) had confounding conditions, including 27 with major substance use, 2 with AIDS-defining CNS conditions, and 9 with severe depression. The spectrum of severity of NCI comprised four $(0.9 \%$ of the overall study sample; $1.1 \%$ of those without confounding conditions) with HAD, 22 (4.9\%; 6.0\%) with MND, and 91 (20\%; 25\%) with ANI.

Seventy-five (17\%) patients reported a decline in ADL caused by cognitive problems, although just over half of these $(42 ; 56 \%)$ did not meet the definition of NCI. Seventy patients $(16 \%)$ reported a decline in ADL caused by physical problems, and there was significant overlap between self-perceived physical and cognitive impairment, with 42 patients attributing their decline in function to both factors.

\section{Clinical, Social and Psychological Factors Associated with Prevalence of NCI}

Analyses of the main explanatory variables are shown in Table 2. The presence of a confounding condition (prevalence ratio $[\mathrm{PR}] 1.51,95 \%$ CI 1.15-1.98), being heterosexual and male (PR 2.03, 95\% CI 1.53-2.69) or female (PR 1.44, 95\% CI 1.04-2.00), and having no university education (PR 1.75, 95\% CI 1.35-2.27) were associated with $\mathrm{NCI}$, there was a weak trend associated with increasing age (PR 1.13 per decade, 95\% CI 1.00-1.29).

Table 3 shows partially and fully-adjusted analyses. University education (adjusted PR [aPR] 0.72, 95\% CI 0.54-0.97) and always being able to afford basic needs (aPR 0.71, 95\% CI 0.54-0.94) were associated with a lower prevalence of NCI. Paradoxically, problem alcohol consumption was also associated with a lower prevalence of NCI (aPR 0.68, 95\% CI 0.46-1.00). Being assessed at the Rome study site (aPR 1.85, 95\% CI 1.31-2.62), a confounding condition (aPR 1.40, 95\% CI 1.03-1.90), and severe depressive symptoms (aPR 1.53, 95\% CI 1.09-2.14) were associated with a higher prevalence of NCI. There was weak evidence for higher prevalence of NCI among patients with a longer time since HIV diagnosis (aPR 1.09 per +5 years, 95\% CI 0.99-1.19) and non-white ethnic groups (aPR 1.36, 95\% CI 0.95-1.97). Analysis of the effects of individual classes of recreational and prescribed drugs found no other correlates of impaired NP function (results not shown). In sensitivity analyses, replacing depressive with anxiety symptoms as a factor in the model did not produce any notable difference in the effect sizes.

Linear regression analyses with the mean $Z$ for all tests as a continuous dependent variable broadly identified the same associated factor of ability to meet basic needs (correlation coefficient $[\beta]+0.31$ increase in $Z$ score, $95 \%$ CI 0.14-0.49), and similar risk factors of duration of HIV infection $(\beta-0.07$ per +5 years, $95 \%$ CI -0.13 to -0.00 ), non-white ethnic group $(\beta-0.40,95 \%$ CI -0.68 to -0.11 ), and study site ( $\beta$ for Rome $-0.52,95 \%$ CI -0.75 to -0.29$)$.

\section{Sensitivity Analyses}

When clinic site was removed as a covariate from the fully adjusted Poisson model, lack of university education and being a heterosexual male showed slightly stronger associations with NCI, although there was little overall difference to the pattern of associations. When participants in Italy were excluded, most adjusted estimates changed little, but there was no longer a statistically significant effect of being able to afford basic needs (aPR 0.77, 95\% CI 0.52-1.13). To investigate the possibility that some component of the battery was driving the high prevalence of $\mathrm{NCI}$ at the Italian site, we compared each test between sites in a linear regression model adjusted for the other important cofactors. Participants in Rome had worse scores on six tests encompassing four out of five cognitive domains 
Table 1 Characteristics of HIV positive study participants by site

\begin{tabular}{|c|c|c|c|c|c|c|}
\hline & $\begin{array}{l}\text { London } \\
(n=292)\end{array}$ & $\begin{array}{l}\text { Rome } \\
(n=90)\end{array}$ & $\begin{array}{l}\text { Copenhagen } \\
(n=42)\end{array}$ & $\begin{array}{l}\text { Minsk } \\
(n=24)\end{array}$ & $\begin{array}{l}\text { Total } \\
(n=448)\end{array}$ & $\begin{array}{l}P \\
\text { value }^{e}\end{array}$ \\
\hline Age, mean (SD) & $46.3(9.0)$ & $47.4(8.2)$ & $46.2(12.3)$ & $32.3(6.8)$ & $45.8(9.6)$ & $<0.001$ \\
\hline Male sex, $\%$ & 92.5 & 65.6 & 92.9 & 41.7 & 84.4 & $<0.001$ \\
\hline MSM, \% & 81.2 & 35.6 & 83.3 & 8.3 & 68.3 & $<0.001$ \\
\hline White ethnicity, $\%$ & 82.9 & 91.1 & 97.6 & 100 & 86.8 & 0.002 \\
\hline Migrant, $\%^{\mathrm{a}}$ & 37.0 & 4.4 & 4.8 & 16.7 & 26.3 & $<0.001$ \\
\hline Can always afford basic needs, $\%$ & 54.1 & 48.9 & 76.2 & 54.2 & 55.1 & 0.025 \\
\hline University educated, \% & 57.9 & 35.6 & 78.6 & 62.5 & 55.6 & $<0.001$ \\
\hline Recent psychoactive drug use, $\%^{\mathrm{b}}$ & 38.0 & 14.4 & 14.3 & 8.3 & 29.5 & $<0.001$ \\
\hline Any previous IDU, $\%$ & 4.5 & 16.7 & 4.8 & 41.7 & 8.9 & $<0.001$ \\
\hline Problem drinking, $\%^{\mathrm{c}}$ & 32.5 & 5.7 & 26.2 & 12.5 & 25.2 & $<0.001$ \\
\hline \multicolumn{7}{|l|}{ Depressive symptoms, $\%^{\mathrm{d}}$} \\
\hline Moderate & 14.4 & 6.2 & 4.8 & 9.1 & 11.7 & \multirow[t]{2}{*}{$<0.001^{\mathrm{f}}$} \\
\hline Severe & 17.2 & 6.2 & 7.1 & 9.1 & 13.8 & \\
\hline \multicolumn{7}{|l|}{ Anxiety symptoms, $\%^{\mathrm{d}}$} \\
\hline Moderate & 15.2 & 11.3 & 4.8 & 4.4 & 12.9 & \multirow[t]{2}{*}{$0.011^{\mathrm{f}}$} \\
\hline Severe & 6.6 & 7.5 & 4.8 & 17.4 & 7.1 & \\
\hline CD4 count, cells/ $\mu \mathrm{L}$, mean (SD) & $597(252)$ & $555(265)$ & 659 (239) & $367(184)$ & $582(256)$ & $<0.001$ \\
\hline Nadir CD4 count, median (IQR) & $360(196,540)$ & $211(112,514)$ & $216(140,360)$ & $186(85,234)$ & $290(160,500)$ & $<0.001$ \\
\hline Years since HIV+ test, median (IQR) & $9.5(5.3,15.4)$ & $10.8(5.5,19.9)$ & $10.3(4.1,19.4)$ & $4.3(1.6,8.0)$ & $9.9(4.8,16.2)$ & 0.004 \\
\hline On ART, \% & 87.3 & 91.1 & 95.2 & 95.8 & 89.1 & 0.34 \\
\hline HIV RNA $<50$ copies/mL, $\%$ & 81.2 & 77.8 & 92.9 & 70.8 & 81.0 & 0.09 \\
\hline $\mathrm{HCV}, \%$ & 13.0 & 18.9 & 4.8 & 29.2 & 14.3 & 0.024 \\
\hline
\end{tabular}

$A R T$ anti-retroviral therapy, $H C V$ hepatitis $\mathrm{C}$ virus, $I D U$ intravenous drug use, $I Q R$ inter-quartile range, $M S M$ men who have sex with men

${ }^{\text {a }}$ Defined as not born in the country of assessment

b Defined as self-reported consumption of opiates for non-medicinal use, amphetamines (including methamphetamine), cocaine, cannabis, ketamine, gamma-hydroxybutyrate, gamma-butyrolactone, psychedelics or mephedrone in the past 3 months

${ }^{\mathrm{c}}$ Problem drinking was defined by the modified (two-question) AUDIT-C questionnaire: a positive score was $\geq 5$ points for men or $\geq 4$ points for women

${ }^{\mathrm{d}}$ Excludes missing data $(\mathrm{n}=12)$

e P-values are derived from Chi squared or Kruskal-Wallis tests of the null hypothesis that each characteristic or variable is the same across all four sites

${ }^{\mathrm{f}}$ Kruskal-Wallis test comparing ordered depression or anxiety symptom scores between sites, using raw scores rather than categories

(choice reaction time, one-back accuracy, Groton maze executive function task, and verbal learning and recall). On a similar analysis of the Minsk participants, it was noted that the mean $Z$ scores for reaction time and choice reaction time tasks were 1.30 and 0.75 lower than the mean for the other three sites, whereas the $Z$ scores for verbal learning and recall tasks were $>1$ SD higher. These slower response times and better verbal learning abilities are difficult to explain and they were only partially attenuated by adjustment for measured confounders. These effects may relate to differences in the technical set-up or the instructions given to participants during the Cogstate battery.

\section{Factors Associated with Impairment of Specific Neuropsychological Tests}

The results of neuropsychological test-specific multivariable analyses are shown in Tables 4 and 5. Only associations with $\mathrm{p}$-values of $<0.005$ are highlighted, to compensate for multiple hypothesis testing. Some notable patterns emerged. First, increasing age was associated with two timed tasks, with verbal learning and recall, and with the maze executive function task. Second, severe depressive symptoms were associated with slower responses on all timed tasks. Third, most inter-site 
Table 2 Unadjusted associations of age, sex, education and comorbid conditions on the prevalence of neurocognitive impairment ${ }^{a}$

\begin{tabular}{|c|c|c|c|}
\hline Variable & $n(\%)$ impaired & Prevalence ratio $(95 \% \mathrm{CI})$ & $P$ \\
\hline \multicolumn{4}{|l|}{ Age, years } \\
\hline Under 35 & $18 / 71(25.4)$ & 1 & \\
\hline $35-50$ & $91 / 246(37.0)$ & $1.46(0.95-2.25)$ & \\
\hline $51-59$ & $35 / 104(33.7)$ & $1.33(0.82-2.15)$ & \\
\hline $60+$ & $12 / 27(44.4)$ & $1.75(0.98-3.14)$ & \\
\hline Per +10 years & & $1.13(1.00-1.29)$ & 0.056 \\
\hline \multicolumn{4}{|c|}{ Sexual orientation and gender } \\
\hline MSM & $91 / 317(28.7)$ & 1 & \\
\hline Heterosexual men & 36/61 (59.0) & $2.03(1.53-2.69)$ & $<0.001$ \\
\hline Women (all) & $29 / 70(41.4)$ & $1.44(1.04-2.00)$ & 0.029 \\
\hline \multicolumn{4}{|l|}{ University educated } \\
\hline No & $91 / 199(45.7)$ & 1 & \\
\hline Yes & $65 / 249(26.1)$ & $0.57(0.44-0.74)$ & $<0.001$ \\
\hline \multicolumn{4}{|c|}{ Confounding condition ${ }^{\mathrm{b}}$} \\
\hline No & $117 / 367(31.9)$ & 1 & \\
\hline Yes & $39 / 81(48.2)$ & $1.51(1.15-1.98)$ & 0.003 \\
\hline \multicolumn{4}{|c|}{ Contributing condition $^{\mathrm{b}}$} \\
\hline No & $131 / 385(34.0)$ & 1 & \\
\hline Yes & $25 / 63(39.7)$ & $1.17(0.83-1.63)$ & 0.37 \\
\hline
\end{tabular}

differences were apparent on language-based tasks (list learning and recall, and verbal fluency), suggesting that although these tests were carried out mainly in the respondent's language, there are important country-specific differences in the performance of the tests. Fourth, patients who were not always able to meet basic needs were impaired in their performance on the CFT and COWAT. Both of these are heavily vocabulary-dependent and this association may indicate a relationship driven by prior educational attainment or by current communication skills, as well as by executive function (all of which factors could impact on patients' employment prospects and socioeconomic status).

\section{Discussion}

In $\mathrm{HIV}+$ patients receiving care at five European HIV clinics, we found that $35 \%$ fulfilled standard criteria for at least mild NCI. Of these, a quarter had conditions that confounded a definitive diagnosis of HAND, more than half had no significant decline in daily function, and the remainder ( $6 \%$ of the total sample) had symptomatic HAND. Our estimates of overall prevalence and the proportion with symptomatic impairment are similar to previous estimates [2-4, 7-9], despite important differences in the target population of those studies and the measuring instruments used. The prevalence of self-reported functional decline associated with cognitive difficulties was half that of measured cognitive impairment on the NP battery, and half of the patients perceiving difficulties had normal cognitive function, indicating weak correlation between the two outcomes. The disconnect between objective function and patients' lived experiences is the subject of a recent study, which concluded that "patient identification of physical versus cognitive causes is poorly associated with objective criteria" [30]. These observations have important implications for classification of HAND in research studies and clinical practice. They also lead to concerns about whether a diagnosis of asymptomatic NCI creates unnecessary anxiety or, as some data suggest [31, 32], heralds future decline.

Limitations to the Frascati criteria, CIPHER study methodology and Cogstate have been discussed in our earlier report on MSM in the UK [23]. In the current analysis, we lacked an HIV-negative control group, and although the normative population data were derived from a healthy sample, we cannot determine whether the high prevalence of NCI is a true effect of HIV infection. Cogstate's own control data are limited by their origin in an 
Table 3 Adjusted associations of psychosocial and clinical variables with prevalence of neurocognitive impairment ${ }^{\text {a }}$

\begin{tabular}{|c|c|c|c|c|}
\hline Variable & PR $(\mathrm{CI})$, partially-adjusted $^{\mathrm{b}}$ & $P$ & PR (CI), fully-adjusted ${ }^{\mathrm{b}}$ & $P$ \\
\hline Age, per +10 years & $1.11(0.97-1.30)$ & 0.12 & $1.03(0.87-1.21)$ & 0.75 \\
\hline University education & $0.63(0.49-0.82)$ & 0.001 & $0.72(0.54-0.97)$ & 0.028 \\
\hline Confounding condition & $1.56(1.19-2.04)$ & 0.001 & $1.40(1.03-1.90)$ & 0.031 \\
\hline Contributing condition & $1.12(0.81-1.56)$ & 0.49 & $1.00(0.68-1.47)$ & 0.99 \\
\hline \multicolumn{5}{|l|}{ Sexual orientation and gender } \\
\hline MSM & 1 & & 1 & \\
\hline Heterosexual men & $1.83(1.39-2.41)$ & & $1.20(0.83-1.73)$ & \\
\hline Women (all) & $1.43(1.02-2.00)$ & $<0.001$ & $0.86(0.57-1.30)$ & 0.23 \\
\hline \multicolumn{5}{|l|}{ Site } \\
\hline London & 1 & & & \\
\hline Rome & $1.60(1.17-2.19)$ & 0.013 & $1.85(1.31-2.62)^{\mathrm{c}}$ & $<0.001$ \\
\hline Copenhagen & $1.01(0.59-1.74)$ & & & \\
\hline Minsk & $0.79(0.37-1.69)$ & & & \\
\hline Non-white ethnicity & $1.40(1.06-1.85)$ & 0.018 & $1.36(0.95-1.97)$ & 0.096 \\
\hline Migrant & $1.13(0.88-1.46)$ & 0.34 & & \\
\hline Can meet basic needs & $0.62(0.48-0.81)$ & $<0.001$ & $0.71(0.54-0.94)$ & 0.017 \\
\hline Recent psychoactive drug use & $0.82(0.59-1.13)$ & 0.22 & & \\
\hline Lifetime IDU & $0.99(0.70-1.41)$ & 0.96 & & \\
\hline Problem drinking ${ }^{\mathrm{d}}$ & $0.56(0.37-0.83)$ & 0.004 & $0.68(0.46-1.00)$ & 0.049 \\
\hline \multicolumn{5}{|l|}{ Depressive symptoms ${ }^{\mathrm{e}}$} \\
\hline None/minimal/mild & 1 & & 1 & \\
\hline Moderate & $1.08(0.70-1.68)$ & & $1.04(0.66-1.64)$ & \\
\hline Severe & $1.49(1.10-2.01)$ & 0.033 & $1.53(1.09-2.14)$ & 0.049 \\
\hline \multicolumn{5}{|l|}{ Anxiety symptoms ${ }^{\mathrm{e}}$} \\
\hline None/mild & 1 & & & \\
\hline Moderate & $1.56(1.16-2.10)$ & & & \\
\hline Severe & $1.21(0.80-1.84)$ & 0.012 & & \\
\hline \multicolumn{5}{|l|}{$\mathrm{CD} 4$ count, cells $/ \mu \mathrm{L}$} \\
\hline$>500$ & 1 & & & \\
\hline $351-500$ & $0.89(0.66-1.21)$ & & & \\
\hline $200-350$ & $0.72(0.47-1.11)$ & & & \\
\hline$<200$ & $1.12(0.71-1.77)$ & 0.40 & & \\
\hline \multicolumn{5}{|l|}{ Nadir CD4 count } \\
\hline$>500$ & 1 & & & \\
\hline $351-500$ & $0.98(0.67-1.44)$ & & & \\
\hline $200-350$ & $0.85(0.58-1.24)$ & & & \\
\hline$<200$ & $1.05(0.75-1.48)$ & 0.65 & & \\
\hline \multicolumn{5}{|l|}{ Years since positive HIV test } \\
\hline Per +5 years & $1.10(1.01-1.20)$ & 0.037 & $1.09(0.99-1.19)$ & 0.090 \\
\hline \multicolumn{5}{|l|}{ VL and ART status ${ }^{\mathrm{e}}$} \\
\hline $\mathrm{VL}<50$ copies $/ \mathrm{mL}$ & 1 & & & \\
\hline Detectable VL on ART & $0.96(0.60-1.54)$ & & & \\
\hline Not on ART & $1.10(0.74-1.64)$ & 0.87 & & \\
\hline Hepatitis $\mathrm{C}$ positive & $0.89(0.65-1.22)$ & 0.47 & & \\
\hline
\end{tabular}


Table 3 continued

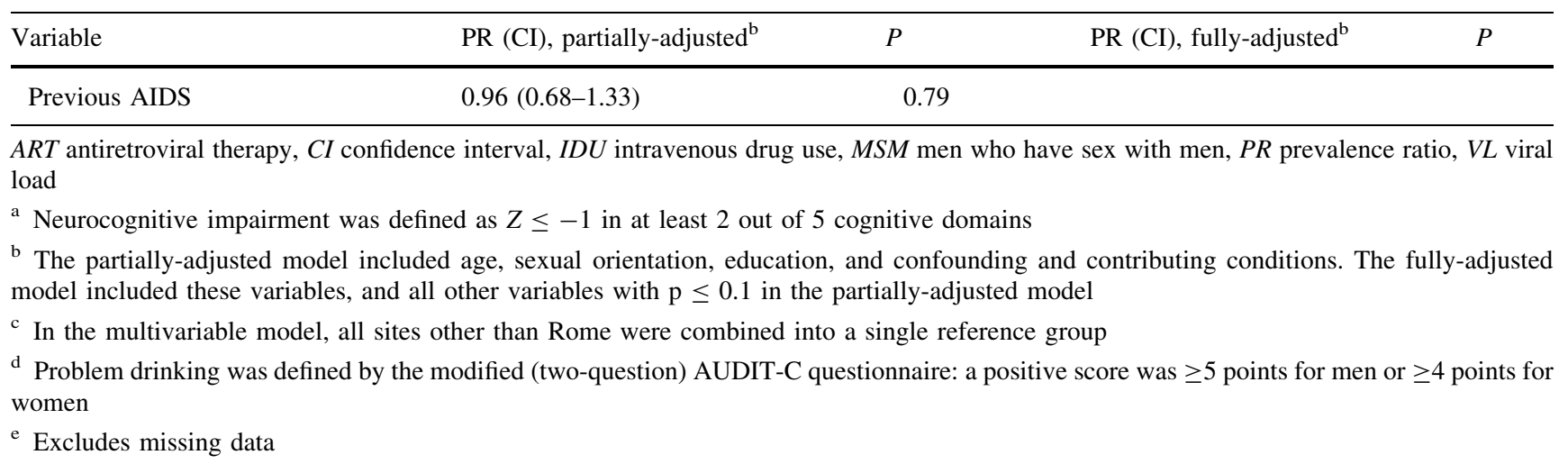

ideal healthy population, but in this respect the platform fares no worse than many traditional neuropsychological tests. The size of the control sample and its distribution according to age, sex and education is adequate for the purpose. Cogstate's main advantage is its widespread usage which allows comparison with other studies. Another limitation is that our sampling strategy may have been biased and led to over-recruitment of particular social groups, patients with concerns about their neuropsychological health, or those with an interest in this field of research. This study only partially achieves the objective of eliciting risk factors relating to social and cultural differences. Our study sample was less diverse in ethnicity and gender than we anticipated.

An unusual feature of our results was the effect of study site, independent of measured confounders. Our sites differed not only linguistically and culturally but also in their race and gender mix, clinical stage, and prevalence of substance use; this is both a limitation and an interesting finding. The effect of site could have been caused by a real difference in characteristics of participants between HIV+ populations at the different sites, by unmeasured confounders, or by local selection biases or differences in assessment technique. This has implications when comparing data from different locations in other studies. The effects were present despite the fact that Cogstate is designed to be culture-neutral and highly standardized. There were differences between the Rome site and others on several different neurocognitive tests, which is less consistent with this being a problem of administration of some part of the battery, although this cannot be ruled out. In sensitivity analyses, we showed a similar pattern of risk factors while accounting for site effects. Our study included a site from Eastern Europe, which is a relatively underresearched region for the study of neurocognitive disorders and HIV in general. We have endeavored to determine the validity of the Cogstate testing platform in the region, by adjusting for known confounders and also through sensitivity analyses. It appeared that patients in Minsk were slower on reaction time tasks but performed better on verbal memory. It is unfortunate that our final sample from Minsk was small and we hope that future studies can explore these findings in this neglected region.

Several factors were found to be associated with NCI. The effect of time since HIV diagnosis on the prevalence of NCI, while weak in our adjusted analysis, has been reported in the START study in a pre-treatment clinical trial population with CD4 counts above 500 cells/ $\mu \mathrm{L}$ [11]. This may reflect chronic neurotoxicity caused by HIV or ART, similar to the effect of nadir CD4 count seen in other patient populations $[5,33]$. These observations concur with the Antiretrovirals, Sexual Transmission Risk and Attitudes (ASTRA) study, in which longer time diagnosed with HIV was strongly associated with physical, psychological and functional difficulties [34]. It is not possible, in this study, to separate out the cohort effect of being diagnosed prior to the development of effective ART in the 1990s, and we note that time since HIV diagnosis is only a proxy for time since infection.

Patients with limited economic means, fewer years' education, and of minority ethnicity were more likely to have NCI, again in keeping with previous work [4, 10, 32, 35-37]. An association between NCI and education was observed despite normalization of $Z$-scores by this factor. This is in keeping with the US Women's Interagency HIV Study, in which there was a greater adverse effect of low reading level in HIV+ than in HIVnegative women [10]. Residual differences associated with educational attainment and social group may indicate that cognitive reserve is important in HIV-associated NCI [38], or they may relate to inadequate standardization of the normative data. Comorbid conditions have also been identified in other studies as risk factors for NCI in HIV positive patients [8, 35, 36]. Age exerted an effect on several different tasks, particularly speed-based tests, where the primary measure was a latency period in 
Table 4 Associations between selected factors and scores obtained on single neuropsychological tests where positive numbers suggest cognitive impairment

\begin{tabular}{|c|c|c|c|c|c|}
\hline Variable & Detection speed $^{\mathrm{a}}$ & Identification speed $^{\mathrm{a}}$ & One-back speed ${ }^{\mathrm{a}}$ & Maze learning $^{\mathrm{b}}$ & Maze recall ${ }^{\mathrm{b}}$ \\
\hline Age (per +10 years) & $20(8,31)$ & $18(8,28)^{\mathrm{d}}$ & $18(6,29)^{\mathrm{c}}$ & $3.8(1.7,5.9)^{\mathrm{d}}$ & $0.7(0.2,1.2)$ \\
\hline \multicolumn{6}{|l|}{ Site } \\
\hline London & Reference & Reference & Reference & Reference & Reference \\
\hline Rome & $29(-0,58)$ & $29(-5,53)$ & $19(-9,47)$ & $6.1(1.0,11.2)$ & $0.5(-0.8,1.8)$ \\
\hline Copenhagen & $10(-23,42)$ & $17(-10,44)$ & $24(-7,55)$ & $-1.6(-7.3,4.2)$ & $-0.8(-2.2,0.6)$ \\
\hline Minsk & $106(56,156)^{\mathrm{d}}$ & $54(12,96)$ & $38(-10,86)$ & $-1.1(-7.8,9.9)$ & $-0.4(-2.6,1.8)$ \\
\hline \multicolumn{6}{|l|}{ Sexual orientation } \\
\hline MSM & Reference & Reference & Reference & Reference & Reference \\
\hline Heterosexual men & $-19(-52,15)$ & $16(-11,44)$ & $-5(-36,27)$ & $3.2(-2.6,9.1)$ & $1.1(-0.3,2.6)$ \\
\hline Women (all) & $4(-28,35)$ & $2(-24,28)$ & $3(-27,33)$ & $0.25(-5.3,5.8)$ & $0.2(-1.2,1.6)$ \\
\hline University education & $-7(-27,13)$ & $-2(-19,15)$ & $-9(-28,11)$ & $-3.2(-6.7,0.4)$ & $-1.0(-1.9,-0.1)$ \\
\hline Confounding condition & $-4(-30,23)$ & $16(-6,38)$ & $14(-11,39)$ & $2.7(-2.0,7.3)$ & $0.0(-1.1,1.2)$ \\
\hline Contributing condition & $2(-26,30)$ & $-3(-26,21)$ & $0(-26,27)$ & $-2.1(-7.0,2.9)$ & $-0.9(-2.1,0.3)$ \\
\hline Non-white ethnic group & $40(9,72)$ & $24(-2,50)$ & $4(-26,34)$ & $8.2(2.7,13.7)^{\mathrm{c}}$ & $2.4(1.0,3.7)^{\mathrm{c}}$ \\
\hline Cannot always meet basic needs & $-2(-22,18)$ & $-7(-23,10)$ & $-18(-37,1)$ & $-2.3(-5.8,1.2)$ & $-0.3(1.2,0.6)$ \\
\hline \multicolumn{6}{|l|}{ Depression } \\
\hline None/mild & Reference & Reference & Reference & Reference & Reference \\
\hline Moderate & $25(-6,55)$ & $27(2,53)$ & $13(-16,42)$ & $-1.5(-6.9,3.9)$ & $0.1(-1.3,1.4)$ \\
\hline Severe & $56(26,86)^{\mathrm{d}}$ & $44(18,69)^{\mathrm{c}}$ & $51(23,80)^{\mathrm{c}}$ & $0.4(-5.0,5.7)$ & $0.9(-0.5,2.2)$ \\
\hline Time since HIV positive (per year) & $18(4,33)$ & $7(-6,19)$ & $8(-6,22)$ & $1.0(-1.6,3.6)$ & $0.8(0.2,1.5)$ \\
\hline Recent recreational drug use & $-4(-27,19)$ & $-7(-26,12)$ & $-12(-34,10)$ & $-1.2(-5.3,2.8)$ & $0.1(-0.9,1.1)$ \\
\hline Problem drinking & $10(-12,33)$ & $8(-11,26)$ & $-0(-21,21)$ & $-3.5(-7.4,-0.5)$ & $-1.2(-2.2,-0.3)$ \\
\hline
\end{tabular}

Tests in this table yield a higher score with worse performance (longer latency or more errors). Associations are expressed as the size of effect on the raw score (95\% confidence interval)

${ }^{a}$ Speed tasks are measured in $\log _{10}$ (latency in milliseconds) $\times 10^{-3}$

b Maze-based tests of executive function are expressed as total number of errors

${ }^{c} \mathrm{P}<0.005$

${ }^{\mathrm{d}} \mathrm{P}<0.001$

milliseconds, and those involving verbal memory. Severe depression also affected timed tasks and unfortunately there are no standard adjustments available for the assessment of patients with mood disorders.

The paradoxical effect of alcohol in this study, where participants with problem drinking were less likely to have NCI, is at odds with the well-established harmful neurological effects of alcohol. We found a similar effect when the results were re-analyzed with the CAGE questionnaire as a means of measuring problem drinking, and the effect did not disappear after adjustment for potential confounders. Selection bias must be considered as a possible explanation. Information bias in our recording of alcohol use could arise from perceived social desirability, or because the modified AUDIT-C fails to capture cumulative lifetime alcohol consumption. It is notable that alcohol use behavior differed markedly between sites, with the UK and Denmark showing much higher rates of problem drinking than Italy and Belarus.
In conclusion, impaired NP performance was frequently present among HIV + patients, although most patients did not report decline in daily function or they had confounding comorbidities to explain their impairment. The discordance between subjective and objective impairment of cognitive function requires further study. A constellation of factors was associated with poorer test scores, including education, socioeconomic circumstances and time since HIV diagnosis. Important outstanding questions in this field relate to the validity of neuropsychological tests and the Frascati criteria when used across linguistically and culturally diverse groups of HIV+ people. Interventions to prevent NCI in PLWH include earlier diagnosis of HIV, earlier initiation of ART, addressing cardiovascular risk factors, and identifying and treating mental health disorders such as depression and substance use. In future work, the CIPHER study will report how our baseline observations predict longer-term changes in neurocognitive function. 
Table 5 Associations between selected factors and scores obtained on single neuropsychological tests where negative numbers suggest cognitive impairment

\begin{tabular}{|c|c|c|c|c|c|}
\hline Variable & One-back accuracy ${ }^{\mathrm{a}}$ & List learning ${ }^{\mathrm{b}}$ & List recall ${ }^{\mathrm{b}}$ & $\mathrm{CFT}^{\mathrm{b}}$ & COWAT $^{b}$ \\
\hline Age (per +10 years) & $0.006(-0.012,0.024)$ & $-1.2^{\mathrm{d}}(-1.6,-0.7)$ & $-0.6^{\mathrm{d}}(-0.9,-0.4)$ & $-0.2(-0.9,0.5)$ & $1.7(0.3,3.2)$ \\
\hline \multicolumn{6}{|l|}{ Site } \\
\hline London & Reference & Reference & Reference & Reference & Reference \\
\hline Rome & $-0.13^{\mathrm{d}}(-0.18,-0.09)$ & $-3.5^{\mathrm{d}}(-4.7,-2.3)$ & $-1.6^{\mathrm{d}}(-2.3,-1.0)$ & $-0.0(-1.7,1.7)$ & $1.3(-2.2,4.8)$ \\
\hline Copenhagen & $-0.011(-0.06,0.04)$ & $-0.8(-2.1,0.5)$ & $-0.8(-1.4,-0.1)$ & $-0.2(-2.1,1.7)$ & $-7.8^{\mathrm{d}}(-11.7,-3.8)$ \\
\hline Minsk & $0.02(-0.06,0.09)$ & $1.0(-1.0,3.0)$ & $0.6(-0.5,1.7)$ & $3.9(0.9,6.8)$ & $-2.0(-8.0,4.1)$ \\
\hline \multicolumn{6}{|l|}{ Sexual orientation } \\
\hline MSM & Reference & Reference & Reference & Reference & Reference \\
\hline Heterosexual men & $-0.06(-0.11,-0.01)$ & $-2.0^{\mathrm{c}}(-3.3,-0.7)$ & $-0.5(-1.2,0.2)$ & $-2.1(-4.1,-0.1)$ & $-5.4(-9.4,-1.3)$ \\
\hline Women (all) & $0.00(-0.05,0.05)$ & $-0.1(-1.4,1.1)$ & $0.4(-0.3,1.1)$ & $-0.6(-2.5,1.2)$ & $1.1(-2.7,4.9)$ \\
\hline University education & $0.008(-0.02,0.04)$ & $0.7(-0.1,1.5)$ & $0.3(-0.1,0.7)$ & $1.5(0.3,2.7)$ & $3.3(0.9,5.8)$ \\
\hline Confounding condition & $0.001(-0.04,0.04)$ & $-0.4(-1.5,0.6)$ & $-0.5(-1.0,0.1)$ & $-2.1(-3.6,-0.5)$ & $-2.3(-5.5,0.9)$ \\
\hline Contributing condition & $0.01(-0.03,0.05)$ & $0.5(-0.6,1.6)$ & $0.1(-0.5,0.7)$ & $-0.5(-2.1,1.2)$ & $2.2(-1.2,5.6)$ \\
\hline Non-white ethnic group & $0.02(-0.03,0.07)$ & $-1.6(-2.8,-0.3)$ & $-0.6(-1.3,0.0)$ & $-2.1(-4.0,-0.3)$ & $-1.3(-5.1,2.5)$ \\
\hline $\begin{array}{l}\text { Cannot always meet basic } \\
\text { needs }\end{array}$ & $-0.01(-0.04,0.02)$ & $-1.0(-1.9,-0.3)$ & $-0.4(-0.9,0.0)$ & $-2.2(-3.4,-1.0)^{\mathrm{d}}$ & $-4.2(-6.6,-1.8)^{\mathrm{d}}$ \\
\hline \multicolumn{6}{|l|}{ Depression } \\
\hline None/mild & Reference & Reference & Reference & Reference & Reference \\
\hline Moderate & $-0.04(-0.09,0.00)$ & $-0.4(-1.6,0.8)$ & $-0.2(-0.9,0.5)$ & $0.9(-0.9,2.7)$ & $-1.8(-5.5,2.0)$ \\
\hline Severe & $-0.05(-0.10,-0.01)$ & $-0.8(-2.0,0.4)$ & $-0.7(-1.4,-0.1)$ & $-0.1(-1.8,1.7)$ & $-1.4(-5.0,2.3)$ \\
\hline $\begin{array}{l}\text { Time since HIV positive } \\
\text { (per }+10 \text { years) }\end{array}$ & $-0.006(-0.03,0.02)$ & $-0.1(-0.7,0.4)$ & $-0.0(-0.4,0.3)$ & $0.4(-0.5,1.3)$ & $0.4(-1.4,2.2)$ \\
\hline $\begin{array}{l}\text { Recent recreational drug } \\
\text { use }\end{array}$ & $-0.04(-0.08,-0.01)$ & $-0.8(-1.7,0.1)$ & $-0.2(-0.7,0.3)$ & $1.0(-0.4,2.4)$ & $0.2(-2.5,3.0)$ \\
\hline Problem drinking & $0.04(0.01,0.08)$ & $0.4(-0.5,1.3)$ & $0.4(-0.0,0.9)$ & $0.9(-0.4,2.2)$ & $2.7(-0.0,5.4)$ \\
\hline
\end{tabular}

CFT category fluency test, COWAT controlled oral word association test

Tests in this table yield a higher score with better performance (better accuracy or more correct responses). Associations are expressed as effect size $(95 \%$ confidence interval)

${ }^{a}$ One-back accuracy is expressed as the arcsine transformation of the square root of the proportion of correct responses

b Verbal fluency tasks and list learning and recall tasks are expressed as total number of valid correct answers

${ }^{c} \mathrm{P}<0.005$

${ }^{\mathrm{d}} \mathrm{P}<0.001$

Acknowledgements The authors acknowledge all study participants for contributing to the study. The CIPHER Study Group includes Andrea Antinori, Pietro Balestra, Tina Bruun, Simon Collins, Marina Daskalopoulou, Jan Gerstoft, Richard Gilson, Lewis Haddow, John Harrison, Graham Hart, Andrzej Horban, Igor Karpov, Fiona Lampe, Rosanna Laverick, Jens Lundgren, Jeffrey McDonnell, Lars Nielsen, Andrew Phillips, Alison Rodger, Lorraine Sherr, Andrew Speakman and Anna Vassilenko. Thanks also go to Adebiyi Aderonke, Nataliya Brima, Christina Broussard, Bill Burman, Simon Edwards, Jonathan Elford, Anna-Maria Geretti, Simon Gilson, Jaqueline Hjetstedt, Anne Johnson, Margaret Johnson, Paul Maruff, Alec Miners, Robert Pralat, Winnie Ann Ryholt, Adrian Schembri, Colette Smith, Rita Trombin and Sonali Wayal. The abstract was translated into Spanish by Alejandro Arenas-Pinto.

Funding The CIPHER Study is supported by the European AIDS Treatment Network, National Institute for Health Research (NIHR) (NEAT Integration Grant 024). The ASTRA study is independent research funded by the NIHR under its Programme Grants for Applied Research funding scheme (RP-PG-0608-10142).

\section{Compliance with Ethical Standards}

Conflict of interest The authors report no disclosures.

Ethical Approval The study was approved by the UK National Research Ethics Service-London Hampstead Committee (11/LO/ 0077), De Videnskabsetiske Komiteér for Region Hovedstaden (H-42011-105), the Ethics Committee of the Minsk Municipal Infectious Diseases Hospital (04/2011), and the Comitato Etico of Istituto Nazionale Malattie Infettive (66/2011). All study participants gave written informed consent prior to commencing the study.

Open Access This article is distributed under the terms of the Creative Commons Attribution 4.0 International License (http://crea tivecommons.org/licenses/by/4.0/), which permits unrestricted use, distribution, and reproduction in any medium, provided you give appropriate credit to the original author(s) and the source, provide a link to the Creative Commons license, and indicate if changes were made. 


\section{References}

1. Bhaskaran K, Mussini C, Antinori A, et al. CASCADE collaboration. Changes in the incidence and predictors of human immunodeficiency virus associated dementia in the era of highly active antiretroviral therapy. Ann Neurol. 2008;63(2):213-21.

2. Simioni S, Cavassini M, Annoni JM, et al. Cognitive dysfunction in HIV patients despite long-standing suppression of viremia. AIDS. 2010;24(9):1243-50.

3. Heaton RK, Clifford DB, Franklin DRJ, et al. HIV-associated neurocognitive disorders persist in the era of potent antiretroviral therapy: CHARTER Study. Neurology. 2010;75(23):2087-96.

4. Bonnet F, Amieva H, Marquant F, et al. Cognitive disorders in HIVinfected patients: are they HIV-related? AIDS. 2013;27(3):391-400.

5. Garvey LJ, Surendrakumar V, Winston A. Low rates of neurocognitive impairment are observed in neuro-asymptomatic HIV-infected subjects on effective antiretroviral therapy. HIV Clin Trials. 2011;12(6):333-8.

6. Crum-Cianflone NF, Moore DJ, Letendre S, et al. Low prevalence of neurocognitive impairment in early diagnosed and managed HIV-infected persons. Neurology. 2013;80(4):371-9.

7. Winston A, Arenas-Pinto A, Stoehr W, et al. Neurocognitive function in HIV infected patients on antiretroviral therapy. PLoS ONE. 2013;8(4):e61949

8. Wright EJ, Grund B, Robertson $\mathrm{K}$, et al. Cardiovascular risk factors associated with lower baseline cognitive performance in HIV-positive persons. Neurology. 2010;75(10):864-73.

9. Bragança M, Palha A. Depression and neurocognitive performance in Portuguese patients infected with HIV. AIDS Behav. 2011;15(8):1879-87.

10. Maki PM, Rubin LH, Valcour VG, et al. Cognitive function in women with HIV: findings from the Women's Interagency HIV Study. Neurology. 2015;84(3):231-40.

11. Wright EJ, Grund B, Cysique LA, et al. Factors associated with neurocognitive test performance at baseline: a substudy of the INSIGHT strategic timing of antiretroviral treatment (START) trial. HIV Med. 2015;16(Suppl 1):97-108.

12. Antinori A, Arendt G, Becker JT, et al. Updated research nosology for HIV-associated neurocognitive disorders. Neurology. 2007;69(18):1789-99.

13. Carey CL, Woods SP, Gonzalez R, et al. Predictive validity of global deficit scores in detecting neuropsychological impairment in HIV infection. J Clin Exp Neuropsychol. 2004;26(3):307-19.

14. Maruff P, Thomas E, Cysique LA, et al. Validity of the Cogstate brief battery: relationship to standardized tests and sensitivity to cognitive impairment in mild traumatic brain injury, schizophrenia, and AIDS dementia complex. Arch Clin Neuropsychol. 2009;24(2):165-78.

15. Overton ET, Kauwe JS, Paul R, et al. Performances on the Cogstate and standard neuropsychological batteries among HIV patients without dementia. AIDS Behav. 2011;15(8):1902-9.

16. Becker JT, Dew MA, Aizenstein HJ, Lopez OL, Morrow L, Saxton J. Concurrent validity of a computer-based cognitive screening tool for use in adults with HIV disease. AIDS Pat Care STDs. 2011;25(6):351-7.

17. Gonzalez R, Heaton RK, Moore DJ, et al. Computerized reaction time battery versus a traditional neuropsychological battery: detecting HIV-related impairments. J Int Neuropsych Soc. 2003;9(1):64-71.

18. Weaver Cargin J, Maruff P, Collie A, Masters C. Mild memory impairment in healthy older adults is distinct from normal aging. Brain Cogn. 2006;60(2):146-55.

19. Harrison J, Maruff P. Measuring the mind: assessing cognitive change in clinical drug trials. Expert Rev Clin Pharmacol. 2008;1(4):471-3.
20. Lim YY, Ellis KA, Harrington K, et al. Use of the Cogstate Brief Battery in the assessment of Alzheimer's disease related cognitive impairment in the Australian imaging, biomarkers and lifestyle (AIBL) study. J Clin Exp Neuropsychol. 2012;34(4):345-58.

21. Cysique LAJ, Maruff P, Darby D, Brew BJ. The assessment of cognitive function in advanced HIV-1 infection and AIDS dementia complex using a new computerised cognitive test battery. Arch Clin Neuropsychol. 2006;21:185-94.

22. Winston A, Puls R, Kerr SJ, et al. Dynamics of cognitive change in HIV-infected individuals commencing three different initial antiretroviral regimens: a randomized, controlled study. HIV Med. 2012;13(4):245-51.

23. McDonnell J, Haddow LJ, Daskalopoulou M, et al. Minimal cognitive impairment in UK HIV positive men who have sex with men: effect of case definitions, and comparison with the general population and HIV negative men. J Acquir Immune Defic Syndr. 2014;67(2):120-7.

24. Ashby J, Foster CJ, Garvey LJ, et al. Cerebral function in perinatally HIV-infected young adults and their HIV-uninfected sibling controls. HIV Clin Trials. 2011;16(2):81-7.

25. Falleti MG, Maruff P, Collie A, Darby DG. Practice effects associated with the repeated assessment of cognitive function using the Cogstate battery at 10-minute, one week and one month test-retest intervals. J Clin Exp Neuropsychol. 2006;28(7):1095-112.

26. Gandhi NS, Skolasky RL, Peters KB, et al. A comparison of performance-based measures of function in HIV-associated neurocognitive disorders. J Neurovirol. 2011;17:159-65.

27. Tombaugh TN, Kozak J, Rees L. Normative data stratified by age and education for two measures of verbal fluency: FAS and animal naming. Arch Clin Neuropsychol. 1999;14(2):167-77.

28. Ruff RM, Light RH, Parker SB, Levin HS. Benton controlled oral word association test: reliability and updated norms. Arch Clin Neuropsychol. 1996;11(4):329-38.

29. Zou G. A modified Poisson regression approach to prospective studies with binary data. Am J Epidemiol. 2004;159(7):702-6.

30. Obermeit LC, Beltran J, Casaletto KB, et al. Evaluating the accuracy of self-report for the diagnosis of HIV-associated neurocognitive disorder (HAND): defining "symptomatic" versus “asymptomatic" HAND. J Neurovirol. 2016.

31. Grant I, Franklin DR, Deutsch R, et al. Asymptomatic HIV-associated neurocognitive impairment increases risk for symptomatic decline. Neurology. 2014;82(23):2055-62.

32. Rourke SB, Gill J, Rachlis A, et al. Asymptomatic neurocognitive impairment (ANI) is associated with progression to symptomatic HIV-associated neurocognitive disorders (HAND) in people with HIV: results from The Ontario HIV Treatment Network (OHTN) cohort study. 8th IAS Conference on HIV Pathogenesis, Treatment \& Prevention. Vol Abstract WEPEB326. Vancouver, Canada, 2015.

33. Ellis RJ, Badiee J, Vaida F, et al. Nadir CD4 is a predictor of HIV neurocognitive impairment in the era of combination antiretroviral therapy. AIDS. 2011;25(14):1747-51.

34. McGowan JA, Sherr L, Rodger AJ, et al. Age, time living with HIV, and self-rated health among people with HIV in the UK. HIV Med. 2016.

35. Heaton RK, Franklin DR, Deutsch R, et al. Neurocognitive change in the era of HIV combination antiretroviral therapy: the longitudinal CHARTER study. Clin Infect Dis. 2015;60(3):473-80.

36. Tozzi V, Balestra P, Serraino D, et al. Neurocognitive impairment and survival in a cohort of HIV-infected patients treated with HAART. AIDS Res Hum Retroviruses. 2005;21(8):706-13.

37. Cole MA, Margolick JB, Cox C, et al. Longitudinally preserved psychomotor performance in long-term asymptomatic HIV-infected individuals. Neurology. 2007;69(24):2213-20.

38. Stern Y. Cognitive reserve. Neuropsychologia. 2009;47(10): 2015-28. 